DEMONSTRATIO MATILEMATICA

$\begin{array}{lll}\text { Vol. XXVII } & \text { No } 1 & 1994\end{array}$

Izabela Foltyńska

\title{
OSCILLATORY PROPERTY FOR THE SYSTEM OF NONLINEAR INTEGRO-DIFFERENTIAL EQUATIONS WITH DEVIATING ARGUMENTS
}

\section{Introduction and preliminaries}

For some ycars increasing intersest has been observed in investigation of propertics of solutions to the integro-differential equations. Levin [4], gave sufficient conditions for unbounded solutions of a class of integro-differential equations to be oscillatory. Asymptolic bchaviour of solutions to the integrodifferential equation has becn considered by S. Nakagiri in [6]. Comparison theorems for systems integro-differential equations with advance arguments are given in [3].

In this paper sufficient conditions for the existence of oscillatory solutions to the system

$$
x_{k}^{\prime}(t)=\int_{0}^{t} f_{k}\left(t, s, x_{1}(s), \ldots, x_{n}(s), x_{1}\left(g_{1}(s)\right), \ldots, x_{n}\left(g_{n}(s)\right)\right) d s
$$

will be established, where $f_{k}: R_{+} \times R_{+} \times R^{n} \times R^{n} \rightarrow R, g_{k}: R_{+} \rightarrow R_{+}$are continuous functions, $g_{k}(t) \leq t, \lim _{t \rightarrow \infty} g_{k}(t)=\infty, k=1, \ldots, n$.

The case $g_{k}(t)>t, k=1, \ldots, n$ for $(A)$ has been considered in [2].

A similar problem for the ordinary difTerential equations is well known, for example see [1], [5], [7].

By a solution $\left\langle x_{1} \ldots, x_{n}\right\rangle=x$ of the system (A) we shall understand only nontrivial solutions extended to the infinity. A solution $x$ of the system (A) is called

- oscillatory, if every component $x_{k}(t), k=1, \ldots, n$ has an infinite sequence of zeros tending to infinity as $t \rightarrow \infty$.

- nonoscillatory, if every component $x_{k}(t), k=1, \ldots, n$ has a constant sign for sufficiently large $t \geq T \geq 0$.

We shall used the following assumptions: 
(i) $\quad f_{k}(t, s, x, v) \operatorname{sgn} v_{k+1} \geq a_{k}(t, s)\left|I I_{k}\left(x_{k+1}\right)\right|, \quad k=1,2, \ldots, n-1$, $f_{n}(t, s, x, v) \operatorname{sgn} v_{1} \leq-a_{n}(t, s)\left|I I_{n}\left(v_{1}\right)\right|$, $x=\left\langle x_{1}(t), \ldots, x_{n}(t)\right\rangle, \quad v=\left\langle x_{1}\left(g_{1}(t)\right), \ldots, x_{n}\left(g_{n}(t)\right)\right\rangle$, $v_{k}=x_{k}\left(g_{k}(t)\right), \quad x_{n+1}=x_{1}$, $I I_{k}\left(v_{k+1}\right) \cdot v_{k+1}>0, I I_{k}^{\prime}\left(v_{k+1}\right) \geq 0, I I_{k}: R \rightarrow R$ are continuous $0<a_{k}(t, s) \in C, k=1, \ldots, n$,

(ii) $\lim _{t \rightarrow \infty} \int_{T}^{t} a_{k}(t, s) d s=\infty, k=1, \ldots, n$,

(iii) $\lim _{t \rightarrow \infty} \int_{T}^{t} \int_{T}^{\tau} a_{k}(\tau, s) d s d \tau=\infty, k=1, \ldots, n-1$,

(iv) $\int_{0}^{T} f_{k}(t, s, x, v) d s=F_{k}(t) \in L_{1}[0, \infty), k=1, \ldots, n,\left|F_{k}(t)\right| \leq K_{k}$, $F_{k}(t) \cdot x_{k+1}\left(t+t_{0}\right)>0, k=1, \ldots, n$,

(v) $\lim _{t \rightarrow \infty} \int_{T}^{t} \int_{T}^{\tau} a_{n}(\tau, s) d s d \tau=\infty$ and notation

$$
M_{k}=\int_{T}^{\infty}\left|F_{k}(t)\right| d t, \quad N_{k}=\inf _{\left\{T_{k}, \infty\right)}\left|I_{k}\left(v_{k}\right)\right| .
$$

\section{Main results}

LEMMA 1. Let (i), (ii) and (iv) hold. If one of the components $x_{i}(1 \leq i \leq n)$ of the solution $x$ to $(\mathrm{A})$ is oscillatory then the solution $x$ is oscillatory.

P roof. Let $x_{k}$ be an oscillatory component of $x$. Suppose that there also exist nonoscillatory components and let $x_{i}$ be a nonoscillatory component with the last index. For the proof let $x_{i}(t)>0$ for $t \geq t_{0}$. Then we have $x_{i}\left(g_{i}(t)\right)>0$ for $t \geq T_{0} \geq t_{0}$. We shall consider the following two cases:

a. For $i \neq 1$, from (A), (i) and (iv) we have

$$
\begin{aligned}
x_{i-1}^{\prime}(t)= & \int_{0}^{t} f_{i-1}\left(t, s, x_{1}(s), \ldots, x_{n}(s), x_{1}\left(g_{1}(s)\right), \ldots, x_{n}\left(g_{n}(s)\right)\right) d s= \\
= & \int_{0}^{T_{0}} f_{i-1}\left(t, s, x_{1}(s), \ldots, x_{n}(s), x_{1}\left(g_{1}(s)\right), \ldots, x_{n}\left(g_{n}(s)\right)\right) d s+ \\
& +\int_{T_{0}}^{t} f_{i-1}\left(t, s, x_{1}(s), \ldots, x_{n}(s), x_{1}\left(g_{1}(s)\right), \ldots, x_{n}\left(g_{n}(s)\right)\right) d s= \\
= & F_{i-1}(t)+\int_{T_{0}}^{t} f_{i-1}\left(t, s, x_{1}(s), \ldots, x_{n}(s), x_{1}\left(g_{1}(s)\right), \ldots, x_{n}\left(g_{n}(s)\right)\right) . \\
& \cdot \operatorname{sgn} x_{i}\left(g_{i}(s)\right) d s \geq \\
\geq & F_{i-1}(t)+\int_{T_{0}}^{t} a_{i-1}(t, s)\left|I_{i-1}\left(x_{i}(s)\right)\right| d s>0 .
\end{aligned}
$$


Hence $x_{i-1}$ is monotonic function and for sufficiently large $t$ has the constant sign. It is a contradiction, since by assumptions $x_{i}$ is the nonoscillatory component with the last index.

b. For $i=1$. Then $x_{1}(t)>0$ for $t \geq t_{0}$ and $x_{1}\left(g_{1}(t)\right)>0$ for $t \geq T_{0}$. From the last equation of the system $(\Lambda),(i)$ and (iv) we have

$$
\begin{aligned}
& x_{n}^{\prime}(t)=\int_{0}^{T_{0}} f_{n}\left(t, s, x_{1}(s), \ldots, x_{n}(s), x_{1}\left(g_{1}(s)\right), \ldots, x_{n}\left(g_{n}(s)\right)\right) d s+ \\
& \quad+\int_{T_{0}}^{t} f_{n}\left(t, s, x_{1}(s), \ldots, x_{n}(s), x_{1}\left(g_{1}(s)\right), \ldots, x_{n}\left(g_{n}(s)\right)\right) \operatorname{sgn} x_{1}\left(g_{1}(s)\right) d s \leq \\
& \quad \leq F_{n}(t)-\int_{T_{0}}^{t} a_{n}(t, s) \mid I I_{n}\left(x_{1}\left(g_{1}(s)\right)\right) d s \leq \\
& \quad \leq K_{n}-N_{n} \int_{T_{0}}^{t} a_{n}(t, s) d l s .
\end{aligned}
$$

By (ii) the right side tends to minus infinity as $t \rightarrow \infty$ and therefore $x_{n}^{\prime}(t)$ $<0$. Ilence $x_{n}$ is monotonic and nondecreasing function and for sufficiently large $t, x_{n}(t)$ has the constant sign.

Let be $x_{n}(t)>0$ for $t \geq t_{0}$. Then $x_{n}\left(g_{n}(t)\right)>0$ for $t \geq T_{n} \geq t_{0}$. From (A), (i) and (iv) we get

$$
x_{n-1}^{\prime}(t) \geq F_{n-1}(t)+\int_{T_{n}}^{t} a_{n-1}(t, s)\left|I_{n-1}\left(x_{n}(s)\right)\right| d s>0 .
$$

Hence $x_{n-1}^{\prime}(t)>0$ and $x_{n-1}(t)$ is the monotonic and increasing function of the constant sign for sufficiently large $t$.

Proceeding in this way, we can prove that the component $x_{k}(t)$ is a monotonic function which contradicts the assumption. Therefore do not exist nonoscillatory components.

Corollary 1. Under the assumptions (i), (ii) and (iv) if one of the component of the solution $x$ to $(A)$ is nonoscillatory then the solution $x$ is nonoscillatory and monolonic.

TIEOREM 1. Let the condilions (i)-(iv) hold. Then every bounded solution of the system (A) is oscillalory.

P r o of. Suppose that there exists a bounded and nonoscillatory solution to (A). Let $x_{k+1}(t)>0$ for $t \geq t_{0} \geq 0$ and $\left|x_{k+1}(t)\right| \leq Q, k=1, \ldots, n$. Then 
$x_{k+1}\left(g_{k+1}(t)\right)>0$ for $t \geq T_{0} \geq t_{0}$. By (i) and (A) we have

$$
x_{k}^{\prime}(t) \geq F_{k}(t)+\int_{T_{0}^{\prime}}^{t} a_{k}(t, s)\left|I_{k}\left(x_{k+1}(s)\right)\right| d s .
$$

Integrating (1) from $T_{0}$ to $t$ and using (iv) we obtain

$$
x_{k}(t)-x_{k}\left(T_{0}\right) \geq \int_{T_{0}}^{t}\left|F_{k}(s)\right| d s+N_{k} \int_{T_{0}}^{t} \int_{T_{0}}^{\tau} a_{k}(\tau, s) d s d \tau
$$

and

$$
x_{k}(t) \geq C+N_{k} \int_{T_{0}}^{t} \int_{T_{0}}^{\tau} a_{k}(\tau, s) d s d \tau, \quad \text { where } C=x_{k}\left(T_{0}\right)+M_{k} .
$$

The right side of this incquality is positive, so is positive the left side. Ilence

$$
Q \geq\left|x_{k}(t)\right| \geq\left|C+N_{k} \int_{T_{0}}^{t} \int_{T_{0}}^{\tau} a_{k}(\tau, s) d s d \tau\right| .
$$

This is a contradiction because the left side of (2) is finite while the right side tends to infinity as $t \rightarrow \infty$. Ilence by Lemma 1 every bounded solution to $(A)$ is oscillatory.

Lemma 2. Let (i)-(iv) hold. Then all nonoscillatory components $x_{k}$, $k=1, \ldots, n$ of a solution $x$ to the system $(\Lambda)$ are monotonic and of the same sign.

Proof. Suppose that $x_{i}(1 \leq i \leq n-2)$ is nonoscillatory component of the solution $x$ to the system (A). For the proof let $x_{i}(t)>0$ for $t \geq t_{0}$. Then also $x_{i}\left(g_{i}(t)\right)>0$ for $t \geq T_{0} \geq t_{0}$. By the Corollary 1 all components of the solution $x$ to the systcm $(A)$ are nonoscillatory. In the case $x_{i}(t)<0$ the proof is analogous.

For $x_{i+1}(t)$ we have the following two posibilitics

$$
x_{i+1}(t)<0 \text { or } x_{i+1}(t)>0 .
$$

$1^{\circ}$ Let $x_{i+1}(t)<0$ for $t \geq t_{i} \geq t_{0}$. Then $x_{i+1}\left(g_{i+1}(t)\right)<0$ for $t \geq T_{i} \geq t_{i}$. From the $i$-th eqation of the system (A), (i) and (iv) we have

$$
x_{i}^{\prime}(t) \leq P_{i}(t)-\int_{T_{i}}^{t} a_{i}(t, s)\left|I_{i}\left(x_{i+1}(s)\right)\right| d s
$$

and

$$
x_{i}^{\prime}(t) \leq K_{i}-N_{i} \int_{T_{i}}^{t} a_{i}(t, s) d s
$$


By (ii) if $t \rightarrow \infty$ then the right side if this inequality tends to minus infinity. Hence $x_{i}^{\prime}(t)<0$.

Integrating (3) from $T_{i}$ to $t$ we obtain

$$
\int_{T_{i}}^{t} \frac{x_{i}^{\prime}(s)\left|I_{i}\left(x_{i+1}(s)\right)\right|}{\left|I_{i}\left(x_{i+1}(s)\right)\right|} d s \leq \int_{T_{i}}^{t} F_{i}(s) d s-\int_{T_{i}}^{t} \int_{T_{i}}^{\tau} a_{i}(\tau, s)\left|I_{i}\left(x_{i+1}(s)\right)\right| d s d \tau .
$$

Since by (iv) $F_{i}(t)<0$, so $\int_{T_{i}}^{t} F_{i}(s) d s=-\int_{T_{i}}^{t}\left|F_{i}(s)\right| d s$.

Then

$$
N_{i} \int_{T_{i}}^{t} \frac{x_{i}^{\prime}(s)}{\left|J I_{i}\left(x_{i+1}(s)\right)\right|} d s \leq-M_{i}-N_{i} \int_{T_{i}}^{t} \int_{T_{i}}^{\tau} a_{i}(\tau, s) d s d \tau
$$

and by (i)

$$
-\int_{T_{i}}^{t} \frac{x_{i}^{\prime}(s)}{I_{i}\left(x_{i+1}(s)\right)} d s \leq-P_{i}-\int_{T_{i}}^{t} \int_{T_{i}}^{\tau} a_{i}(\tau, s) d s d \tau, \quad P_{i}=\frac{M_{i}}{N_{i}},
$$

whence

$$
\int_{T_{i}}^{t} \frac{x_{i}^{\prime}(s)}{I_{i}\left(x_{i+1}(s)\right)} d s \geq P_{i}+\int_{T_{i}}^{t} \int_{T_{i}}^{\tau} a_{i}(\tau, s) d s d \tau .
$$

Integrating by parts the left side we have

$$
\begin{aligned}
\frac{x_{i}(t)}{I_{i}\left(x_{i+1}(t)\right)}+\int_{T_{i}}^{t} \frac{x_{i}(s) I I_{i}^{\prime}\left(x_{i+1}(s)\right) x_{i+1}^{\prime}(s)}{I I_{1}^{\prime}\left(x_{i+1}(s)\right)} d s \geq \\
\geq C_{i}+\int_{T_{i}}^{t} \int_{T_{i}}^{\tau} a_{i}(\tau, s) d s d \tau, \quad C_{i}=\frac{x_{i}\left(T_{i}\right)}{I I_{i}\left(x_{i+1}\left(T_{i}\right)\right)}+P_{i} .
\end{aligned}
$$

Since the right side is positive, so the left one must be also positive. Hence

$$
x_{i+1}^{\prime}(t)>0 \text {. }
$$

Now, $x_{i+2}(t)$ is either positive or negative.

If $x_{i+2}(t)<0$ for $t \geq t_{i+1} \geq t_{i}$ and also $x_{i+2}\left(g_{i+2}(t)\right)<0$ for $t \geq T_{i+1} \geq$ $\geq t_{i+1}$ then from the $i+1-$ th cqation of the system $(A)$ we get

$$
\begin{aligned}
x_{i+1}^{\prime}(t)= & \int_{0}^{T_{i+1}} f_{i+1}\left(t, s, x_{1}(s), \ldots, x_{n}(s), x_{1}\left(g_{1}(s)\right), \ldots, x_{n}\left(g_{n}(s)\right)\right) d s+ \\
& +\int_{T_{i+1}}^{t} f_{i+1}\left(t, s, x_{1}(s), \ldots, x_{n}(s), x_{1}\left(g_{1}(s)\right), \ldots, x_{n}\left(g_{n}(s)\right)\right) d s=
\end{aligned}
$$




$$
\begin{aligned}
= & F_{i+1}(t)-\int_{T_{i+1}}^{t} \int_{i+1}\left(t, s, x_{1}(s), \ldots, x_{n}(s), x_{1}\left(g_{1}(s)\right), \ldots, x_{n}\left(g_{n}(s)\right)\right) . \\
& \cdot \operatorname{sgn} x_{i+2}\left(g_{i+2}(s)\right) d s \leq \\
\leq & F_{i+1}(t)-\int_{T_{i+1}}^{t} a_{i+1}(t, s)\left|I_{i+1}\left(x_{i+2}(s)\right)\right| d s .
\end{aligned}
$$

Ilence by (iv)

$$
x_{i+1}^{\prime}(t) \leq K_{i}-N_{i+1} \int_{T_{i+1}}^{t} a_{i+1}(t, s) d s .
$$

By (ii) the right side of (5) tends to minus infinity as $t \rightarrow \infty$, so $x_{i+1}^{\prime}(t)<0$. It is a contradiction with(1). Therclore $x_{i+2}(t)>0$ for $t \geq t_{i+1}$.

$2^{\circ}$ If $x_{i+2}(t)>0$ for $t \geq t_{i+1}$ then from the $i+1-$ th eqation of the system (A) we get

$$
x_{i+1}^{\prime}(l) \geq F_{i+1}(t)+N_{i+1} \int_{T_{i+1}}^{t} a_{i+1}(t, s) d s .
$$

By (ii) if $t \rightarrow \infty$ then the right side of (6) tends to infinity and $x_{i+1}^{\prime}(t)>0$. Integrating (6) from $T_{i+1}$ to $t$ we obtain

$$
x_{i+1}(t) \geq x_{i+1}\left(T_{i+1}\right)+M_{i+1}+N_{i+1} \int_{T_{i+1}}^{t} \int_{T_{i+1}}^{\tau} a_{i+1}(\tau, s) d s d \tau
$$

By (ii) if $t \rightarrow \infty$ then the right side of (7) tends to infinity. Therefore $x_{i+1}(t)>0$.

Moreover from the i-th eqation of (A) and by (i) and (iv)

$$
x_{i}^{\prime}(t) \geq-K_{i}+N_{i} \int_{T_{i}}^{t} a_{i}(t, s) d s .
$$

By (ii) if $t \rightarrow \infty$ then the right side of (s) tends to infinity. Therefore $x_{i}^{\prime}(t)>0$.

In this way we have prove that $x_{i}(t), i=1, \ldots, n$ are positive and monotonic and $x_{i}^{\prime}(t)>0$ for $i=1, \ldots n-1, x_{n}^{\prime}(t)<0$.

Theorem 2. Let (i)-(v) hold. Then all solutions of the system (A) are oscillatory.

P roof. Under assumptions (i)-(iv) by Lemma 2 it follows that components $x_{i}, i=1, \ldots, n$ of a solution $x$ to the systcm $(\Lambda)$ are monotonic and $x_{i}(t)>0$ for $i=1, \ldots, n$. 
But from the last equation of (A), (i) and (iv) we have

$$
x_{n}^{\prime}(t) \leq F_{n}(l)-N_{n} \int_{T_{n}}^{t} a_{n}(t, s) d s .
$$

By (ii) if $t \rightarrow \infty$ then the right side of the above inequality tends to minus infinity and by (iv) $x_{n}^{\prime}(t)<0$. Integrating (9) from $T_{n}$ to $t$ we have

$$
x_{n}(t) \leq x_{n}\left(T_{n}\right)+M_{n}-N_{n} \int_{T_{n}}^{t} \int_{T_{n}}^{\tau} a_{n}(\tau, s) d s d \tau .
$$

By (v) the right side tends to minus infinity. Therefore $x_{n}(t)<0$. It is a contradiction. In Lemma 2 under assumptions (i)-(iv) we obtained $x_{i}(t)>0$ for $i=1, \ldots, n$. IIence and by Lcmma 1 it follows that under assumptions (i) $-(\mathrm{v})$ all components are oscillatory.

Remark 1. Theorem 2 is also valid for $(A)$ with advance arguments but the assumption (iv) is not necded.

Lemma 3. Let (i)-(iv) hold. If the component $x_{i}(1 \leq i \leq n)$ of the solution $x$ to the system $(\Lambda)$ salisfies the following condition

$$
\lim _{t \rightarrow \infty} \inf \left|x_{i}(t)\right|=L \quad 1 \leq i \leq n
$$

then

$$
\lim _{t \rightarrow \infty} x_{k}(t)= \begin{cases}\infty & \text { for } L>0 \\ -\infty & \text { for } L<0, k=1, \ldots, i-1, i>1\end{cases}
$$

and

$$
\lim _{t \rightarrow \infty} \inf \left|x_{k}(l)\right|=0 \quad \text { for } L<\infty, k=i+1, \ldots, n .
$$

Proof. Let $L>0$, (it is also for $L=\infty$ ). Then by Corollary 1 the solution in nonoscillatory and monotic. For the proof let $x_{i}(t)>0$ for $t \geq T \geq t_{0}$. (In the case $x_{i}(t)<0$ the proof is analogous). From (A), (i) and (iv) it follows that

$$
x_{i-1}^{\prime}(t) \geq F_{i-1}(t)+\int_{T}^{t} a_{i-1}(t, s)\left|I I_{i-1}\left(x_{i}(s)\right)\right| d s>0 .
$$

On the other hand integrating (10) from $T$ to $t$ and using (iv) we obtain

$$
x_{i-1}(t) \geq x_{i-1}(T)+M_{i-1}+N_{i-1} \int_{T}^{t} \int_{T}^{\tau} a_{i-1}(\tau, s) d s d \tau
$$

and $\lim _{t \rightarrow \infty} x_{i-1}(t)=\infty$. 
Similarly we may prove that $\lim _{t \rightarrow \infty} x_{k}(t)=\infty$ for $k=1, \ldots, i-1$. In the case $L<\infty$ we shall show that

$$
\lim _{t \rightarrow \infty} \inf \left|x_{k}(t)\right|=0 \quad k=i+1, \ldots, n .
$$

Suppose that there cxists a component $x_{m}(i<m \leq n)$ such that

$$
\lim _{t \rightarrow \infty} \inf \left|x_{m}(\ell)\right|=L=\infty \text {. }
$$

From first part of the proof it follows that

$$
\lim _{t \rightarrow \infty}\left|x_{k}(t)\right|=L=\infty \quad \text { for } k=1, \ldots, i, \ldots, m-1
$$

which contradicts that $L<\infty$ for $k=i+1, \ldots, m-1$. Therefore $\lim _{t \rightarrow \infty}$ $\inf \left|x_{k}(t)\right|=0$ for $k=i+1, \ldots, n$.

Lемма 4. Let (i)-(iv) hold. Then for every nonoscillatory solution $x$ of the system (A) there is a number $i(1 \leq i \leq n)$ such that $n+i$ is even and for sufficiently large $t \geq T \geq 0$ we have

$$
\begin{gathered}
x_{1}(t) x_{k}(t)>0, \quad k=1, \ldots, i, \\
(-1)^{n+k} x_{1}(t) x_{k}(t)>0, \quad k=i+1, \ldots, n
\end{gathered}
$$

and

$$
\begin{gathered}
x_{k+1}(l) x_{k}^{\prime}(l)>0, \quad k=1, \ldots, i-1, \\
(-1)^{n+k+1} x_{k+1}(l) x_{k}^{\prime}(t)>0, \quad k=i, i+1, \ldots, n .
\end{gathered}
$$

Pro of. Let $x$ be a nonoscillatory solution of $(A)$. Then from Corollary 1 it follows the existence of a point $T \geq t_{0} \geq 0$ such that $x_{k}(t)$ and $x_{k}\left(g_{k}(t)\right)$, $k=1, \ldots, n$ are monotonic and of a constant sign for $t \geq T$. Let $x_{1}(t)>0$ for $t \geq T$. (In the case $x_{1}(t)<0$ the proof is analogous).

We shall show that $x_{n}(t)>0$ for $t \geq T$. Suppose that $x_{n}(t)<0$. Then from (A), (i) and (iv) it follows that

$$
\lim _{t \rightarrow \infty} \inf x_{n}(l)=L<0 .
$$

Now, by Lemma $3 \lim _{t \rightarrow \infty} x_{k}(l)=-\infty, k_{i}=1, \ldots, n-1$ which contradicts to the assumption $x_{1}(t)>0$ for $t \geq T$. Thercfore $x_{n}(t)>0$ for $t \geq T$.

Now, consider the sign of $x_{n-1}(t)$. There arc two possibilitics $x_{n-1}(t)>0$ or $x_{n-1}(t)<0$ for $t \geq T$. From (A), (i) and (iv) we have

$$
x_{n-1}^{\prime}(t) \geq F_{n-1}(t)+\int_{T}^{t} a_{n-1}(t, s)\left|I I_{n-1}\left(x_{n}(s)\right)\right| d s>0 .
$$

If $x_{n-1}(t)>0$ and $x_{n-1}^{\prime}(t)>0$ then $\lim _{t \rightarrow \infty} x_{n-1}(t)=L>0$ and by Lemma $3 \lim _{t \rightarrow \infty} x_{k}(t)=\infty, k=1, \ldots, n-2$. Therefore the incqualities (11) are true for $i=n$. 
In the case when $x_{n-1}(t)<0$ for $t \geq T$ and $x_{n-1}^{\prime}(t)>0$ we shall show that $x_{n-2}(t)>0$. Suppose that $x_{n-2}(l)<0$. Then from (A), (i) and (iv) we have

$$
x_{n-2}^{\prime}(t) \leq F_{n-2}(t)-N_{n-2} \int_{T}^{t} a_{n-2}(t, s) d s .
$$

Hence $\lim _{t \rightarrow \infty} x_{n-2}^{\prime}(t)<0$ and if $x_{n-2}(t)<0$ then $\lim _{t \rightarrow \infty} x_{n-2}(t)=L<0$, and by Lemma $3 \lim _{t \rightarrow \infty} x_{k}(l)=-\infty, k=1, \ldots, n-3$, which contradicts to the assumption $x_{1}(t)>0$. IIence $x_{n-2}(t)>0$ for $t \geq T$.

If $x_{n-3}(t)>0$ for $t \geq T$, then the incquality (11a) holds for $i=n-2$ and the inequality (11b) for $i>n-2$.

Proceeding similarly as above we prove that the incqualities (11) are true for $i(1 \leq i \leq n)$ such that $i+n$ is even.

The incqualities (12) can be proved in a similar way as inequalities (11).

Theorem 3. Let (i)-(iv) hold. Moreover

$$
\begin{aligned}
\int_{T}^{\infty} \int_{T}^{\tau_{0}} a_{i}\left(\tau_{0}, t_{0}\right) \mid I_{i}\left(\int_{g_{i+1}\left(t_{1}\right)}^{\infty} \int_{T}^{\tau_{1}} a_{i+1}\left(\tau_{1}, t_{1}\right) \mid I_{i+1}\left(\int_{g_{i+2}\left(t_{2}\right)}^{\infty} \times\right.\right. \\
\quad \times \int_{T}^{\tau_{2}} a_{i+2}\left(\tau_{2}, t_{2}\right) \mid I_{i+2}\left(\ldots\left|I_{n-1} \int_{g_{n}\left(t_{n-i}\right)}^{\infty} \int_{T}^{\tau_{n-i}} a_{n}\left(\tau_{n-i}, t_{n-i}\right)\right| \times\right. \\
\quad \times I_{n}\left(\int_{T}^{g_{1}\left(t_{n-i+1}\right)} \int_{T}^{\tau_{n-i+1}} a_{1}\left(\tau_{n-i+1}, t_{n-i+1}\right) \mid I_{1} \int_{T}^{g_{2}\left(t_{n-i+2}\right)} \times\right. \\
\quad \times \int_{T}^{\tau_{n-i+2}} a_{2}\left(\tau_{n-i+2}, t_{n-i+2}\right) \mid I I_{2}\left(\ldots \mid I I_{i-3}\left(\alpha \int_{T}^{g_{i-2}\left(t_{n-2}\right)} \times\right.\right. \\
\quad \times \int_{T}^{\tau_{n-2}} a_{i-2}\left(\tau_{n-2}, t_{n-2}\right) d t_{n-2} d d \tau_{n-2}\left|\ldots d t_{n-i} d \tau_{n-i}\right| \ldots \\
\quad \ldots\left|d t_{1} d d \tau_{1}\right| d l_{0} d d \tau_{0}=\infty
\end{aligned}
$$

for an arbitrary $\alpha=$ const $\neq 0$.

Then every solution of the systcm $(A)$ is

a. oscillatory for cren $n$,

b. either oscillatory or tcnding monotonically to zcro as $t \rightarrow \infty$ for odd $n$.

Proof. Assume that the system (A) has a nonoscillatory solution $x$. Let $T_{0} \geq 0$ be a point suclı that the functions $x_{k}(t)$ and $x_{k}\left(g_{k}(t)\right), k=1, \ldots, n$ 
have a constant sign for $t \geq T_{0}$. Next we cloose a point $T \geq T_{0}$ such that $g_{k}(t) \geq T_{0}, k=1, \ldots, n$ for $t \geq T$.

a. If $n$ is even then by Lemma 4 there is an even positive number $i$ such that the inequalities (11) and (12) are satisfied. If $\lim _{t \rightarrow \infty} x_{i}(t)=L$ then by Lemma 3 we have

$$
\lim _{t \rightarrow \infty} x_{k}(t)= \begin{cases}\infty & \text { for } k=1, \ldots, i-1 \\ 0 & \text { for } k:=i+1, \ldots, n .\end{cases}
$$

From (11) it follows that $x_{i+1}(t)<0$ for $t \geq T$. IIcnce by (i) and (iv) we get

$$
\begin{aligned}
x_{i}^{\prime}(t)= & \int_{0}^{T} f_{i}\left(t, s, x_{1}(s), \ldots, x_{n}(s), x_{1}\left(g_{1}(s)\right), \ldots, x_{n}\left(g_{n}(s)\right)\right) d s- \\
& -\int_{T}^{t} f_{i}\left(t, s, x_{1}(s), \ldots, x_{n}(s), x_{1}\left(g_{1}(s)\right), \ldots, x_{n}\left(g_{n}(s)\right)\right) \times \\
& \times \operatorname{sgn} x_{i+1}\left(g_{i+1}(s)\right) d s \leq F_{i}(t)-\int_{T}^{t} a_{i}(t, s)\left|I_{i}\left(x_{i+1}(s)\right)\right| d s<0 .
\end{aligned}
$$

Integrating from $T$ to $\infty$ the last inequality we obtain

$$
x_{i}(\infty)-x_{i}(T) \leq \int_{T}^{\infty} F_{i}(s) d s-\int_{T}^{\infty} \int_{T}^{\tau} a_{i}(\tau, s)\left|I I_{i}\left(x_{i+1}(s)\right)\right| d s d \tau
$$

Ilence by (iv) we have

$$
x_{i}(T) \geq-\int_{T}^{\infty} F_{i}(s) d s+\int_{T}^{\infty} \int_{T}^{\tau} a_{i}(\tau, s)\left|I I_{i}\left(x_{i+1}(s)\right)\right| d s d \tau
$$

and

$$
\begin{aligned}
\infty>x_{i}(T) & \geq \int_{T}^{\infty}\left|F_{i}(s)\right| d l s+\int_{T}^{\infty} \int_{T}^{\tau} a_{i}(\tau, s)\left|I_{i}\left(x_{i+1}(s)\right)\right| d s d \tau \geq \\
& \geq M_{i}+\int_{T}^{\infty} \int_{T}^{\tau} a_{i}(\tau, s)\left|I I_{i}\left(x_{i+1}(s)\right)\right| d s d \tau .
\end{aligned}
$$

Hence

$$
\int_{T}^{\infty} \int_{T}^{\tau} a_{i}(\tau, s)\left|I I_{i}\left(x_{i+1}(s)\right)\right| d s d \tau<\infty
$$

From (11) it follows that $x_{i+2}(t)>0$, so for $k=i+1$ we get

$$
x_{i+1}^{\prime}(t) \geq F_{i+1}(l)+\int_{T}^{t} a_{i+1}(t, s)\left|I_{i+1}\left(x_{i+2}(s)\right)\right| d s .
$$


Integrating from $g_{i+1}(t)$ to $\infty$ this incquality and by (iv) we obtain

$$
\left|x_{i+1}\left(g_{i+1}(t)\right)\right| \geq \int_{g_{i+1}(t)}^{\infty} \int_{T}^{\tau} a_{i+1}(\tau, s)\left|I_{i+1}\left(x_{i+2}(s)\right)\right| d s d \tau .
$$

Proceeding in the same way for $k=i+2, \ldots, n$ we have

(15) $\left|x_{k}\left(g_{k}(t)\right)\right| \geq \int_{g_{k}(t)}^{\infty} \int_{T}^{\tau} a_{k}(\tau, s)\left|J I_{k}\left(x_{k+1}(s)\right)\right| d s d \tau, \quad k=i+1, \ldots, n$.

Consider the remaining cquations for $k=1, \ldots, i-2$.

Now from (11a) we know that if $x_{1}(t)>0$, then $x_{k}(t)>0$ for $k=2, \ldots, i-2$. Therefore from first equation of the system (A) we get

$$
x_{1}^{\prime}(t) \geq F_{1}(t)+\int_{T}^{t} a_{1}(t, s)\left|I_{1}\left(x_{2}(s)\right)\right| d s .
$$

Integrating from $T$ to $g_{k}(l)$ the above incquality and by (iv) we have

$$
\left|x_{1}\left(g_{1}(t)\right)\right| \geq \int_{T}^{g_{1}(\ell)} \int_{T}^{\tau} a_{1}(\tau, s)\left|J I_{1}\left(x_{2}(s)\right)\right| d s d \tau .
$$

Procceding in the same way for $k=2, \ldots, i-2$ we get

(16) $\left|x_{k}\left(g_{k}(t)\right)\right| \geq \int_{T}^{g_{k}(t)} \int_{T}^{r} a_{k}(\tau, s)\left|I I_{k}\left(x_{k+1}(s)\right)\right| d s d \tau, \quad k=1, \ldots, i-2$.

Applying (15) to (14) we get

$$
\begin{aligned}
\infty>\int_{T}^{\infty} \int_{T}^{\tau_{0}} a_{i}\left(\tau_{0}, t_{0}\right) \mid & I_{i}\left(\int_{g_{i+1}\left(t_{1}\right)}^{\infty} \int_{T}^{\tau_{1}} a_{i+1}\left(\tau_{1}, t_{1}\right) \mid I I_{i+1}\left(\int_{g_{i+2}\left(t_{2}\right)}^{\infty} \times\right.\right. \\
\times & \int_{T}^{\tau_{2}} a_{i+2}\left(\tau_{2}, t_{2}\right) \ldots \mid I_{n-1}\left(\int_{g_{n}\left(t_{n}\right)}^{\infty} \int_{T}^{\tau_{n}} a_{n}\left(\tau_{n-i}, t_{n-i}\right) \mid \times\right. \\
\times & I_{n}\left(x_{1}\left(g_{1}\left(t_{n-i}\right)\right)\right)\left|d t_{n-i} d \tau_{n-i} \ldots\right| d t_{2} d \tau_{2} \ldots \mid d t_{0} d \tau_{0} .
\end{aligned}
$$

Using (15) to the above incquality we get

$$
\infty>\int_{T}^{\infty} \int_{T}^{\tau_{0}} a_{i}\left(\tau_{0}, t_{0}\right) \mid I_{i}\left(\int_{g_{i+1}\left(t_{1}\right)}^{\infty} \int_{T}^{\tau_{1}} a_{i+1}\left(\tau_{1}, t_{1}\right) \mid I I_{i+1}\left(\int_{g_{i+2}\left(t_{2}\right)}^{\infty} \times\right.\right.
$$




$$
\begin{aligned}
& \times \int_{T}^{\tau_{2}} a_{i+2}\left(\tau_{2}, t_{2}\right) \ldots\left|I_{i+2}\right|\left(\ldots \mid I I_{n-1}\left(\int_{g_{n}\left(t_{n-i}\right)}^{\infty} \int_{T}^{\tau_{n-i}} a_{n}\left(\tau_{n-i}, t_{n-i}\right) \mid \times\right.\right. \\
& \times I_{n}\left(\int_{T}^{g_{1}\left(t_{n}-i+1\right)} \int_{T}^{\tau_{n}-i+1} a_{1}\left(\tau_{n-i+1}, t_{n-i+1}\right) \mid I_{1}\left(\int_{T}^{g_{2}\left(t_{n-i+2}\right)} \times\right.\right. \\
& \times \int_{T}^{\tau_{n-i+2}} a_{2}\left(\tau_{n-i+2}, t_{n-i+2}\right) \mid I_{2}\left(\ldots I _ { i - 3 } \left(\int_{T}^{g_{i-2}\left(t_{n-2}\right)} \times\right.\right. \\
& \times \int_{T}^{\tau_{n-2}} a_{i-2}\left(\tau_{n-2}, t_{n-2}\right)\left|I I_{i-2}\left(x_{i-1}\left(t_{n-2}\right)\right)\right| d t_{n-2} d \tau_{n-2} \mid \ldots \\
& \ldots d t_{n-i} d \tau_{n-i}\left|\ldots d l_{1} d \tau_{1}\right| d t_{0} d \tau_{0} \geq \int_{g_{i}(T)}^{\infty} \int_{T}^{\tau_{0}} a_{i}\left(\tau_{0}, t_{0}\right) \mid I I_{i} \ldots I_{i-3} \times \\
& \times\left(\alpha \int_{T}^{g_{i-2}\left(t_{n-2}\right)} \int_{T}^{\tau_{n-2}} a_{i-2}\left(\tau_{n-2}, l_{n-2}\right) d l_{n-2} d \tau_{n-2} \mid \ldots\right. \\
& \ldots\left|d t_{n-i} d \tau_{n-i}\right| \ldots \mid d l_{0} d \tau_{0}=\infty \text {, } \\
& \text { where } \alpha=-\left|I I_{i-2}\left(x_{i-1}(T)\right)\right|, i=2, \ldots, n \text {. }
\end{aligned}
$$
latory.

We get the contradiction. If $n$ is even then every solution to $(A)$ is oscil-

b. If $n$ is odd then by Jcmma 4 there cxists an odd positive integer $i(1 \leq i \leq n)$ such that $n+i$ is an even number and inequalities (11) are satisfied.

Similarly as in the case $a$. We may show that when $1<i \leq n$ then all solutions of $(A)$ arc oscillatory.

Let us consider the case $i=1$. IIence $\lim _{t \rightarrow \infty} x_{1}(t)=L$. If $|L|<\infty$ then be Lemma 3 we have $\lim _{t \rightarrow \infty} x_{k}(t)=0, k=2, \ldots, n$. We will show that $\lim _{t \rightarrow \infty} x_{1}(t)=0$ too, i.c. $L=0$.

Suppose on the contrary that $|L|>0$. Then for $t \geq T_{1},\left|x_{1}\left(g_{1}(t)\right)\right| \geq p$ $>0$. From (A) and (i)-(iv) for $i=2$ wc have

$$
x_{2}^{\prime}(t) \geq F_{2}(t)+\int_{T}^{t} a_{2}(t, s)\left|H_{2}\left(x_{3}(s)\right)\right| d s .
$$

Integrating (17) from $g_{2}\left(T_{1}\right)$ to $\infty$ we obtain 


$$
\infty>\left|x_{2}\left(g_{2}\left(T_{1}\right)\right)\right| \geq \int_{g_{2}\left(T_{1}\right)}^{\infty} \int_{T_{1}}^{\tau} a_{2}(\tau, s)\left|I_{2}\left(x_{3}(s)\right)\right| d s d \tau .
$$

Integrating the remaining equations from $g_{k}(t)$ to $\infty$ we have

$$
\left|x_{k}\left(g_{k}(t)\right)\right| \geq \int_{g_{k}(t)}^{\infty} \int_{T_{1}}^{\tau} a_{k}(\tau, s)\left|I_{k}\left(x_{k+1}(s)\right)\right| d s d \tau, \quad k=3, \ldots, n
$$

Using (19) to (18) and by monotonicaly of functions $I I_{k}$ we have

$$
\begin{aligned}
& \infty>\left|x_{2}\left(g_{2}\left(T_{1}\right)\right)\right| \geq \int_{g_{2}\left(T_{1}\right)}^{\infty} \int_{T_{1}}^{\tau_{0}} a_{2}\left(\tau_{0}, t_{0}\right) \mid I_{2}\left(\int_{g_{3}\left(t_{1}\right)}^{\infty} \int_{T}^{\tau_{1}} a_{3}\left(\tau_{1}, t_{1}\right) \mid I_{3}\left(\int_{g_{4}\left(t_{2}\right)}^{\infty} x\right.\right. \\
& \times \int_{T}^{\tau_{2}} a_{4}\left(\tau_{2}, t_{2}\right) \mid I_{1} \ldots I_{n-1}\left(\int_{g_{n}\left(t_{n-2}\right)}^{\infty} \int_{T}^{\tau_{n}-2} a_{n}\left(\tau_{n-2}, t_{n-2}\right) \times\right. \\
& \times\left|I I_{n}\left(x_{1}\left(g_{1}\left(t_{n-2}\right)\right)\right)\right| d l t_{n-2} d \tau_{n-2}|\ldots| d l_{1} d \tau_{1} \mid d t_{0} d \tau_{0} \geq \\
& \geq \int_{g_{2}(T)}^{\infty} \int_{T}^{\tau_{0}} a_{2}\left(\tau_{0}, t_{0}\right) \mid I_{2}\left(\int_{g_{3}\left(t_{1}\right)}^{\infty} \int_{T}^{\tau_{1}} a_{3}\left(\tau_{1}, t_{1}\right)\left|I_{3} \int_{g_{4}\left(t_{2}\right)}^{\infty} \int_{T}^{\tau_{2}} a_{4}\left(\tau_{2}, t_{2}\right)\right| I I_{4} \ldots\right. \\
& \ldots \mid I I_{n-1}\left(\alpha \int_{g_{n}\left(t_{n-2}\right)}^{\infty} \int_{T}^{\tau_{n}-2} a_{n}\left(\tau_{n-2}, t_{n-2}\right) d t_{n-2} d \tau_{n-2}|\ldots| d t_{1} d \tau_{1} \mid d t_{0} d \tau_{0},\right.
\end{aligned}
$$

where $\alpha=-\left|I I_{n}(p)\right| \neq 0$.

The above inequality contradicts to (13) and $L=0$. Ilence every nonoscillatory solution to $(A)$ tends to zero for $t \rightarrow \infty$.

\section{R.cfercuces}

[1] F. V. Atkinson: On sccond-order non-lincar oscillalions, Pacific J. Math. 5 (1955), 643-648.

[2] I. Foltyíska: Oscillatory solutions of the systcm of $n$ integro-differential equations with devialing arguments, Functiones et Approximatio 19 (1990), 97-105.

[3] I. Folt y íska: Comparison theorems for syslems inlcgro-differential equations with advance arguments, Demonstratio Math. 25 (1992), 219-227.

[4] J. J. Levin: Boundedncss and oscillation of some Vollerra and delay equations, J. Diff. Equat. 5 (1969), 369-39s.

[5] J. D. Mirzov: On some analogs of Sturm's and Kneser's theorems for nonlinear systems, J. Matl. Anal. Appl. 53 (1970), 418-125.

[6] S. Nakagiri: Oscillalory propcrlics for Vollerra intcgro-differential equations of higher order, Math. Sem. Notes, 6 (1978), 537-544. 
[7] N. V. Varech, V. N. S li c velo: On the conditions of the oscillation of the solutions of differential equations systcm wilh rclarlcl arguments, The qualitalive melhods of the Theory of difjerential equalions wilh devialing arguments, Inst. Math. Acad. Science USSR, Kiev (1977), 26-44, (in Russian).

\section{INSTITUTE OF MATHEMIATICS}

TECIINICAL UNIVERSITY OF POZNAN

Piotrowo 3a

60.963 POZNAŃ, POLAND

Received August 23, 1991. 